\title{
NITROGÊNIO E SATURAÇÃO POR BASES NO DESEMPENHO DO CAPIM- POJUCA (Paspalum atratum Swalen cv. Pojuca) CULTIVADO EM VASOS ${ }^{1}$
}

\author{
Nitrogen and base saturation in the performance of pojuca grass \\ (Paspalum atratum Swalen cv. Pojuca) grown in pots
}

\author{
Ana Cristina Wyllie Elyas ${ }^{2}$, José Cardoso Pinto ${ }^{3}$ \\ Antônio Eduardo Furtini Neto ${ }^{4}$, Augusto Ramalho de Morais ${ }^{5}$
}

\begin{abstract}
RESUMO
Objetivou-se avaliar o crescimento e a produção de MS do capim-Pojuca cultivado em Gleissolo háplico. O experimento foi conduzido em casa-de-vegetação do Departamento de Ciência do Solo da UFLA, Lavras - MG. A semeadura foi realizada em vasos plásticos, sem furos, com capacidade para $4 \mathrm{dm}^{3}$ de solo cada. Os tratamentos consistiram de quatro doses de $\mathrm{N}(0,100,200$ e 400 $\mathrm{mg} / \mathrm{dm}^{3}$ ) e quatro níveis de saturação por bases do solo (40, 50, 60 e $\left.80 \%\right)$. Os tratamentos foram dispostos em um delineamento de blocos ao acaso, em esquema fatorial 4 x 4, com quatro repetições. Foram efetuados três cortes da forragem a cerca de $4 \mathrm{~cm}$ de altura do solo. Antes da realização do primeiro corte, foram avaliadas as taxas de surgimento de perfilhos (TSP), de alongamento de perfilhos (TAlP) e de aparecimento de folhas (TApF) do capim-Pojuca. Também foram avaliadas a densidade de perfilhos (DP) e a produção de matéria seca (MS), nos três cortes. As TSP e TAlP responderam de maneira significativa ao aumento das doses de N, enquanto a TApF foi indiferente ao suprimento de N. A adubação nitrogenada proporcionou aumentos na DP e na produção de MS da gramínea nos três cortes efetuados. Não foi observada resposta significativa das variáveis estudadas ao aumento dos níveis de saturação por bases do solo. Conclui-se que a aplicação de $200 \mathrm{mg} / \mathrm{dm}^{3}$ de $\mathrm{N}$ é indispensável para um bom crescimento e boa produção de MS do capim-Pojuca, sendo desnecessário elevar o nível de saturação por bases do solo acima de $40 \%$ em Gleissolo háplico.
\end{abstract}

Termos para indexação: Densidade de perfilhos, produção de MS, taxa de alongamento de perfilhos, taxa de aparecimento de folhas, taxa de surgimento de perfilhos.

\begin{abstract}
This work aimed to evaluate the growth and dry matter production of Pojuca grass grown in haplic Gleysol. The experiment was carried out in greenhouse of the Soil Science Department of the Universidade Federal de Lavras, Lavras, MG, Brazil. The sowing of seeds was performed in plastic pots without holes, with a capacity of $4 \mathrm{dm}^{3}$ each of soil. The treatments consisted of four doses of $\mathrm{N}\left(0,100,200\right.$ and $\left.400 \mathrm{mg} / \mathrm{dm}^{3}\right)$ and four levels of base saturation $(40,50,60$ and $80 \%)$. The experimental design was in a randomized complete blocks, making up a 4 x 4 factorial scheme with four replicates. Three cuts at the height of $4 \mathrm{~cm}$ from soil level were proceed. Previous for the first cut, the tiller appearance rate (TAR), tiller elongation rate (TER) and leaf appearance rate (LAR) were studied. Also, dry matter (DM) yield and tiller density (TD) were assessed. The $\mathrm{N}$ doses increased $(\mathrm{P}<0.05)$ morphogenic variables TAR and TER, whereas no significance $(\mathrm{P}>0.05)$ was observed for LAR. Nitrogen fertilization provided increases in TD and DM yield of Pojuca grass. No significant response was observed for increased levels of base saturation of the soil for the studied variables. It was concluded that application of $\mathrm{N}$ is indispensable for a good growth and good DM production of the Pojuca grass, being not needed to raise the base saturation level of the soil above $40 \%$ in haplic Gleysol.
\end{abstract}

Index terms: Dry matter yield, leaf appearance rate, tiller appearance rate, tiller density, tiller elongation rate.

(Recebido em 22 de novembro de 2004 e aprovado em 1 de setembro de 2005)

\section{INTRODUÇÃO}

Os sistemas de produção de leite, carne e lã no Brasil são predominantemente baseados em pastagens. Os estudos de avaliação de espécies e cultivares de gramíneas e leguminosas forrageiras objetivando a sua adaptabilidade aos diversos ecossistemas brasileiros têm possibilitado a liberação de inúmeros materiais e o estabelecimento de pastagens de maior produção de massa verde, de melhor valor nutritivo, conseqüentemente proporcionando maior produção animal.

O gênero Papalum da família Graminae ou Poaceae conta com cerca de 400 espécies espalhadas pelas regiões Centro Sul do Brasil, leste da Bolívia, Paraguai, Norte da Argentina e Uruguai (QUARIM et al., 1997). No território brasileiro são encontradas diversas espécies, entre elas

\footnotetext{
${ }_{1}^{1}$ Parte da Dissertação de Mestrado do primeiro autor para a obtenção do título de Mestre em Zootecnia, Forragicultuta e Pastagem, da Universidade Federal de Lavras/UFLA.

${ }^{2}$ Zootecnista, Mestre em Zootecnia e Doutoranda em Zootecnia na Universidade Federal Lavras/UFLA - Cx. P. 3037 - $37200-000$ - Lavras, MG.

${ }^{3}$ Professor, Doutor, do Departamento de Zootecnia da Universidade Federal de Lavras/UFLA - Cx. P. 3037 - 37200-000 - Lavras, MG - Bolsista do CNPq josecar@ufla.br

${ }^{4}$ Professor, Doutor, do Departamento de Ciência do Solo da Universidade Federal Lavras/UFLA - Cx. P. 3037 - $37200-000$ - Lavras, MG - Bolsista do CNPq.

${ }^{5}$ Professor, Doutor, do Departamento de Ciências Exatas da Universidade Federal de Lavras/UFLA - Cx. P. 3037 - 37200-000 - Lavras, MG - Bolsista do CNPq.
} 
algumas de interesse forrageiro como Paspalum notatum Flügge, P. plicatulum Mich $x, P$. guenoarum Arech, $P$. dilatatum Poir, entre outras (PUPO, 1995).

A espécie Paspalum atratum Swalen, vulgarmente conhecida como capim-Pojuca, apresenta estabelecimento por sementes, adaptação a solos ácidos e de baixa fertilidade, boa produção de massa verde, boa aceitabilidade pelos animais e alta digestibilidade da matéria seca (MS) (KALMBACHER \& KRETSCHMER, 1995). Adaptada a solos mal-drenados (EMBRAPA, 2000; KALMBACHER et al., 1997; KALMBACHER \& KRETSCHMER, 1995), essa forrageira desperta interesse para o estabelecimento via sementes em solos úmidos, resultando em mais uma alternativa de alimento para os rebanhos, tornando a atividade pecuária mais produtiva e lucrativa.

Um importante ponto a ser avaliado nos testes de um material forrageiro é o nível de utilização de nutrientes a fim de otimizar a produção e diminuir os custos de implantação e manutenção das pastagens, considerando o retorno econômico diante das técnicas de correção e adubação. De acordo com Siqueira (1986), a necessidade da calagem é dependente da interação do solo com a espécie forrageira. Costa et al. (1998) observaram que as maiores produções de MS do capimPojuca foram obtidas nos tratamentos com calagem acrescida de aplicações de N, P, K e S.

A adubação das pastagens, principalmente a nitrogenada, está entre os fatores mais importantes para determinar o nível de produção por unidade de área (PRIMAVESI et al., 2001). Além de uma possível melhora no valor nutritivo da planta forrageira, a fertilização nitrogenada propicia uma maior produção de MS em função do aumento de massa foliar, perfilhos novos e longevidade das folhas (CORSI \& NÚSSIO, 1994). O efeito da adubação nitrogenada é reportado em diversos trabalhos realizados com forrageiras tropicais. Acosta (2001) observou incremento da produção de MS com a elevação das doses de $\mathrm{N}$ em Paspalum dilatatum Poir. Neres et al. (2004) observaram como efeitos da adubação nitrogenada, o aumento da produção de MS, número de perfilhos e altura do dossel em cultivares de Brachiaria brizanta Stapf. Da mesma forma Soares et al. (2003) observaram aumento da produção de MS em Panicum maximum Jacq. cv. Tanzânia à medida em que se elevou a dosagem de $\mathrm{N}$.

Objetivou-se neste trabalho determinar o nível adequado de saturação por bases (V\%) do solo e a melhor dose de $\mathrm{N}$ para o crescimento do capim-Pojuca, cultivado em Gleissolo háplico em vasos, em casa-devegetação.

\section{MATERIAL E MÉTODOS}

O trabalho foi conduzido de setembro de 2000 a fevereiro de 2001 em casa-de- vegetação do Departamento de Ciência do Solo (DCS) da Universidade Federal de Lavras (UFLA), Lavras, MG, situada a $918 \mathrm{~m}$ de altitude, nas coordenadas de $21^{\circ} 14^{\prime}$ de latitude sul e $45^{\circ} 00^{\prime}$ de longitude oeste de Greenwich.

Foi utilizado o delineamento experimental de blocos ao acaso, a fim de diminuir o efeito da variação da incidência de raios solares dentro da casa-de-vegetação. Os tratamentos, constituindo um fatorial $4 \times 4$, corresponderam a quatro níveis de saturação por bases (V\%) $(40,50,60$ e $80 \%)$ e quatro doses de $\mathrm{N}(0,100,200$ e $400 \mathrm{mg} / \mathrm{dm}^{3}$ ), com quatro repetições. Foram empregados 16 vasos plásticos por tratamento, sem furos, com capacidade para $4,0 \mathrm{dm}^{3}$ de solo cada, perfazendo 64 vasos (unidades experimentais).

O solo utilizado no ensaio foi um Gleissolo háplico, (anteriormente, Glei pouco húmico), coletado no Campus da UFLA, a uma profundidade de $0-20 \mathrm{~cm}$, destorroado e peneirado, ao ar livre, em peneira de malha de 2,0 $\mathrm{mm}$. Uma amostra desse solo foi coletada e enviada para análises química e física nos Laboratórios do DCS - UFLA.

A calagem para se elevar a saturação por bases em pH 7,0 nos quatro níveis pré-estabelecidos (40, 50, 60 e $80 \%$ ) foi realizada aplicando-se em cada vaso 0 ; 1,$94 ; 3,88$ e 7,76 g de calcário dolomítico calcinado com PRNT $100 \%$, respectivamente. A adubação de manutenção, constituída de $300 \mathrm{mg} / \mathrm{dm}^{3}$ de $\mathrm{P} ; 150 \mathrm{mg} /$ $\mathrm{dm}^{3}$ de $\mathrm{K} ; 50 \mathrm{mg} / \mathrm{dm}^{3}$ de $\mathrm{S} ; 0,8 \mathrm{mg} / \mathrm{dm}^{3}$ de B; $1,5 \mathrm{mg} / \mathrm{dm}^{3}$ de $\mathrm{Cu} ; 3,6 \mathrm{mg} / \mathrm{dm}^{3}$ de $\mathrm{Mn}$ e $5,0 \mathrm{mg} / \mathrm{dm}^{3}$ de $\mathrm{Zn}$ foi realizada de acordo com a CFSEMG (1999), mediante interpretação das análises do solo.

Após a calagem e a adubação de manutenção, foi realizada uma segunda coleta de solo, em cada vaso, sendo feita uma amostra composta dos 16 vasos de cada tratamento, cujos resultados estão apresentados na Tabela 1.

A semeadura foi realizada 40 dias após a calagem com sementes puras, viáveis, fornecidas pela Embrapa Cerrados, sendo utilizadas 10 a 15 sementes por vaso, permanecendo cinco plantas em cada vaso após o desbaste efetuado 15 dias depois do plantio. Os vasos foram irrigados diariamente com água deionizada, mantendo-os em $80 \%$ da sua capacidade de campo através de pesagens periódicas. 
TABELA 1 -Características químicas do Gleissolo háplico nos níveis de saturação por bases original (40\%), 50, 60 e 80\%.

\begin{tabular}{lrrrr}
\hline \multicolumn{1}{c}{ Atributo } & V 40\%* & V 50\% & V 60\% & V 80\% \\
\hline $\mathrm{pH}$ & 5,0 & 5,2 & 5,5 & 6,4 \\
$\mathrm{P}\left(\mathrm{mg} / \mathrm{dm}^{3}\right)$ & 1,6 & 72,0 & 87,0 & 84,0 \\
$\mathrm{~K}^{+}\left(\mathrm{mg} / \mathrm{dm}^{3}\right)$ & 47,0 & 161,0 & 184,0 & 172,0 \\
$\mathrm{Ca}^{2+}\left(\mathrm{cmolc}^{3} \mathrm{dm}^{3}\right)$ & 2,7 & 4,4 & 4,7 & 6,4 \\
$\mathrm{Mg}^{2+}\left(\mathrm{cmolc}^{3} \mathrm{dm}^{3}\right)$ & 1,3 & 1,3 & 1,5 & 1,0 \\
$\mathrm{Al}^{3+}\left(\mathrm{cmolc}^{3} \mathrm{dm}^{3}\right)$ & 0,5 & 0,3 & 0,2 & 0,0 \\
$\mathrm{H}^{+}+\mathrm{Al}^{3+}\left(\mathrm{cmolc}^{2} \mathrm{dm}^{3}\right)$ & 5,6 & 25,6 & 5,0 & 3,6 \\
$\mathrm{P} \mathrm{resina}\left(\mathrm{mg} / \mathrm{dm}^{3}\right)$ & 27,3 & 82,5 & 113,5 & 179,0 \\
$\mathrm{SB}\left(\mathrm{cmolc} / \mathrm{dm}^{3}\right)$ & 4,1 & 6,1 & 6,7 & 3,6 \\
$\mathrm{t}\left(\mathrm{cmolc} / \mathrm{dm}^{3}\right)$ & 4,6 & 6,4 & 6,9 & 7,8 \\
$\mathrm{~T}\left(\mathrm{cmolc} / \mathrm{dm}^{3}\right)$ & 9,7 & 11,7 & 11,7 & 7,8 \\
$\mathrm{~m} \%$ & 10,8 & 4,7 & 2,9 & 0,0 \\
$\mathrm{~V} \%$ & 42,4 & 52,2 & 57,2 & 68,5 \\
\hline
\end{tabular}

*Valores dos atributos do solo nativo, apresentando, ainda, 3,7 dag/kg de matéria orgânica e 45,0, 28,0 e 27,0\%, respectivamente, de areia, silte e argila (textura média).

A adubação nitrogenada teve início 15 dias após o plantio, junto com o desbaste. $\mathrm{O} \mathrm{N}$ fornecido às plantas de P. atratum foi sob a forma de nitrato de amônio, em solução, fracionado e aplicado totalmente antes do primeiro corte, a cada quatro dias, para que fossem completadas as doses de 100,200 e $400 \mathrm{mg} / \mathrm{dm}^{3}$ de $\mathrm{N}$ como descrito a seguir: Dose $100 \mathrm{mg} / \mathrm{dm}^{3}$ : duas aplicações de $25 \mathrm{mg} / \mathrm{dm}^{3}$ (cada uma contendo $0,714 \mathrm{~g} / \mathrm{dm}^{3}$ de $\mathrm{NH}_{4} \mathrm{NO}_{3}$ ); uma aplicação de $50 \mathrm{mg} / \mathrm{dm}^{3}$ (contendo $1,428 \mathrm{~g} / \mathrm{dm}^{3}$ de $\mathrm{NH}_{4} \mathrm{NO}_{3}$ ). Dose 200 $\mathrm{mg} / \mathrm{dm}^{3}$ : duas aplicações de $25 \mathrm{mg} / \mathrm{dm}^{3}$ (cada uma contendo $0,714 \mathrm{~g} / \mathrm{dm}^{3}$ de $\mathrm{NH}_{4} \mathrm{NO}_{3}$ ); três aplicação de $50 \mathrm{mg} / \mathrm{dm}^{3}$ (cada uma contendo $1,428 \mathrm{~g} / \mathrm{dm}^{3}$ de $\mathrm{NH}_{4} \mathrm{NO}_{3}$ ). Dose 400 $\mathrm{mg} / \mathrm{dm}^{3}$ : duas aplicações de $25 \mathrm{mg} / \mathrm{dm}^{3}$ (cada uma contendo $0,714 \mathrm{~g} / \mathrm{dm}^{3}$ de $\mathrm{NH}_{4} \mathrm{NO}_{3}$ ); cinco aplicação de $50 \mathrm{mg} / \mathrm{dm}^{3}$ (cada uma contendo $1,428 \mathrm{~g} / \mathrm{dm}^{3}$ de $\mathrm{NH}_{4} \mathrm{NO}_{3}$ ); uma aplicação de $100 \mathrm{mg} / \mathrm{dm}^{3}$ de $\mathrm{N}$ (contendo $2,856 \mathrm{~g} / \mathrm{dm}^{3}$ de $\mathrm{NH}_{4} \mathrm{NO}_{3}$ ).

O escalonamento da adubação foi realizado face ao elevado índice salino do fertilizante nitrato de amônio (105), sendo, portanto, capaz de remover a água das células vegetais para a solução do solo, atingindo principalmente sementes e plantas jovens, levando as mesmas à morte (VALE et al., 1997).

O perfilho principal de uma das cinco plantas de cada vaso foi marcado com fio colorido para o estudo do crescimento de folhas e de perfilhos, de acordo com
Chapman \& Lemaire (1993). Os perfilhos individualizados foram medidos com régua milimetrada, do nível do solo até a lígula da folha mais jovem. Registrou-se o número de folhas daquele perfilho e o número de perfilhos de sua touceira. Foram efetuadas 12 observações para cada variável, espaçadas de três dias, anteriormente ao primeiro corte. As taxas de surgimento de perfilhos (TSP = perfilhos/ dia), alongamento de perfilhos (TAlP $=\mathrm{cm} / \mathrm{dia})$ e de aparecimento de folhas $(\mathrm{TApF}=$ folhas/dia/perfilho) foram calculadas pela subtração dos respectivos valores obtidos em cada avaliação pelo valor da observação anterior, e dividido pelo número de dias de cada intervalo de leitura (três dias). Todos os perfilhos de cada vaso foram contados antes de cada corte para a obtenção da densidade de perfilhos (DP).

Devido ao lento estabelecimento e desenvolvimento das plantas observado durante o período experimental e considerando a necessidade de se obter material suficiente para as análises bromatológicas, principalmente nos vasos que não receberam adubação nitrogenada, o primeiro corte foi feito com nove semanas após a semeadura e o segundo e terceiro, com seis semanas de intervalo, correspondendo a 63, 105 e 147 dias após a semeadura. Os cortes foram realizados com tesoura de poda a aproximadamente $4 \mathrm{~cm}$ de altura do solo. Depois do corte, o material vegetal de cada vaso foi pesado, colocado em

Ciênc. agrotec., Lavras, v. 30, n. 3, p. 554-561, maio/jun., 2006 
saco de papel e levado para o Laboratório de Pesquisa Animal do Departamento de Zootecnia da UFLA para a realização da análise de MS, de acordo com AOAC (1990). $\mathrm{O}$ rendimento de MS por vaso foi calculado, corrigindose o rendimento de massa verde de cada vaso pelo seu teor de MS.

Os efeitos dos tratamentos sobre as variáveis estudadas foram avaliados de acordo com a análise de variância, baseando-se no seguinte modelo estatístico:

$$
\gamma_{i j k}=\mu+B_{i}+S_{j}+\mathbf{N}_{k}+\mathbf{S N}_{j k}+\mathbf{E}_{i j k} \text { em que: }
$$

$\mathrm{Y}_{\mathrm{ijk}}$ = observação referente à dose $\mathrm{k}$ de $\mathrm{N}$ no nível $\mathrm{j}$ de saturação por bases no bloco i;

$\mu=$ média geral do experimento;

$\mathrm{B}_{\mathrm{i}}=$ efeito do bloco $\mathrm{i}$, com $\mathrm{i}=1,2,3$ e 4;

$\mathrm{S}_{\mathrm{j}=}$ efeito do nível $\mathrm{j}$ de saturação por bases, $\operatorname{com} \mathrm{j}=1,2,3$ e 4; $\mathrm{N}_{\mathrm{k}}=$ efeito da dose $\mathrm{k}$ de $\mathrm{N}$, com $\mathrm{k}=1,2,3$ e 4;

$\mathrm{SN}_{\mathrm{jk}}=$ efeito da interação do nível $\mathrm{j}$ de saturação por bases com a dose $\mathrm{k}$ de $\mathrm{N}$;

$\mathrm{E}_{\mathrm{ijk}}=$ erro experimental associado a observação $\mathrm{Y}_{\mathrm{ijk}}$

Foram efetuadas análises de regressão das variáveis quando se detectou efeito significativo dos tratamentos. As análises de variância e de regressão foram realizadas utilizando-se o programa computacional SISVAR (FERREIRA, 1999).

\section{RESULTADOS E DISCUSSÃO}

No presente trabalho, as variáveis estudadas não foram influenciadas pela elevação dos níveis de saturação por bases acima de V 40\%. Segundo Vilela et al. (1998), o capim-Pojuca se adapta às condições de baixa fertilidade do solo, estando classificado em grau médio de exigência, com uma recomendação de calagem para elevação da saturação por bases para 30 a $35 \%$.

Houve resposta significativa da taxa de surgimento de perfilhos - TSP $(\mathrm{P}<0,01)$ do capim-Pojuca somente para as doses de $\mathrm{N}$ aplicadas. A média geral obtida foi de 0,292 perfilhos/dia, com um intervalo médio de tempo entre o surgimento de perfilhos sucessivos de 3,42 dias. Com um comportamento quadrático, a máxima TSP ocorreu com a aplicação de $333,5 \mathrm{mg} / \mathrm{dm}^{3}$ de $\mathrm{N}$, equivalente a uma produção de 0,452 perfilhos/dia ou 2,21 dias/perfilho (Figura 1).

O aparecimento do primeiro perfilho ocorreu por volta do $19^{\circ}$ dia após a semeadura, emergindo da axila da $4^{\mathrm{a}}$ folha. Aproximadamente 20 dias após o desbaste (35 dias após a semeadura), cessou a emissão de perfilhos nos vasos que não foram submetidos à adubação nitrogenada. $\mathrm{O}$ aparecimento de um novo perfilho ocorreu a cada 3,47 ; 2,59 e 2,65 dias para as doses 100, 200 e $400 \mathrm{mg} / \mathrm{dm}^{3}$ de N, respectivamente.

A taxa de aparecimento dos perfilhos e o seu tempo de vida são características importantes para a persistência da comunidade de plantas na pastagem. Estudos demonstram que o número de perfilhos e a duração do processo de perfilhamento são variáveis entre as diferentes espécies de gramíneas (CARNEVALLI, 2003; SANTOS et al., 2003; SBRISSIA, 2004).

Após a aplicação de $333,5 \mathrm{mg} / \mathrm{dm}^{3}$ de $\mathrm{N}$, ocorreu diminuição na TSP, possivelmente por excesso do referido nutriente. Além disso, pode ter havido competição por luz, devido à alta produção de folhas em uma pequena área. Pinto et al. (1994) observaram que com área foliar elevada há menor penetração de luz na base das touceiras, prejudicando a formação de novos perfilhos.

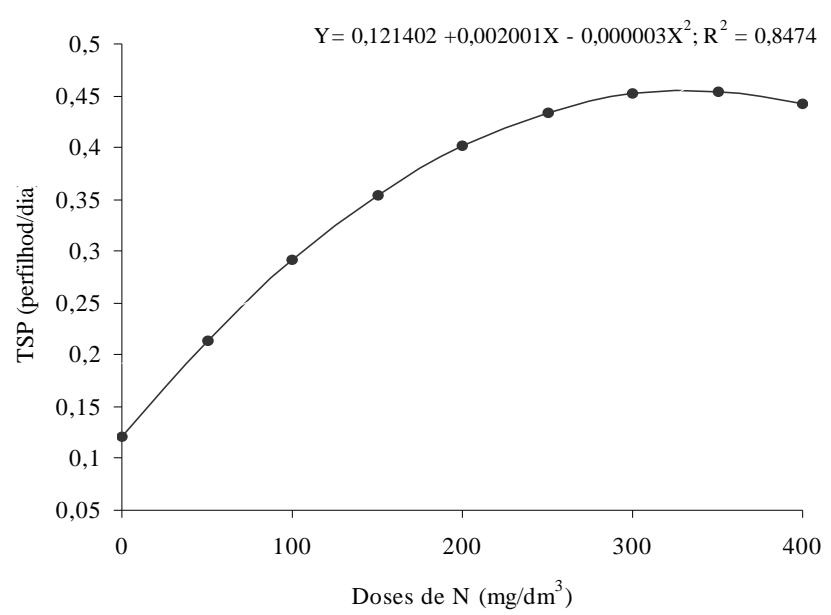

FIGURA 1 - Representaçao graııca, equaçao ae regressao e coenıcıente ae aetermınaçao para a taxa de surgimento de perfilhos (TSP) do capim-Pojuca em função de doses de N. 
A taxa de alongamento de perfilho (TAIP) do capimPojuca respondeu de maneira significativa $(\mathrm{P}<0,01)$ às doses de $\mathrm{N}$ aplicadas. Na Figura 2, mostra-se a dinâmica do crescimento de perfilhos nas diferentes doses de N, apresentando média de crescimento de $0,126 \mathrm{~cm} / \mathrm{dia}$. A máxima TAlP foi observada com a aplicação de $244,5 \mathrm{mg} /$ $\mathrm{dm}^{3} \mathrm{de}$ N. A altura final dos perfilhos foi de 3,5; 5,0; 7,0 e 6,0 $\mathrm{cm}$ para as doses $0,100,200$ e $400 \mathrm{mg} / \mathrm{dm}^{3}$ de $\mathrm{N}$, respectivamente. Em um trabalho clássico publicado em 1972, Langer (1972) afirma que a adubação nitrogenada promove aumento da velocidade de crescimento, acarretando, conseqüentemente, em maior elongação do colmo. Por volta do $20^{\circ}$ dia após o desbaste, cessou a TAlP das plantas que não receberam adubação nitrogenada.

Coelho (1994) encontrou valores similares aos desse trabalho, avaliando o comprimento de perfilhos de grama batatais (Paspalum notatum Flügge), desde a base até o ponto de inserção da folha mais jovem, sob as adubações fosfatada e nitrogenada aos 30, 60 e 90 dias após o plantio, sendo que a altura variou entre $3,17 \mathrm{~cm}$ aos 30 dias até um máximo de $10,0 \mathrm{~cm}$ aos 90 dias de idade.

A análise de variância não detectou efeito significativo dos tratamentos sobre a taxa de aparecimento de folhas (TApF) do capim-Pojuca. Segundo Gastal \& Lemaire (1988), em espécies de gramíneas cespitosas, o efeito da nutrição de $\mathrm{N}$ na TApF é muito pequeno, sendo mais expressivo no tamanho da folha, levando a um importante aumento na taxa de alongamento foliar. A média geral da TApF foi de 0,083 folhas/dia, sendo, portanto, necessários 12,04 dias para o surgimento de uma folha no perfilho.

Avaliando o desenvolvimento de Paspalum urvillei Steud. implantado em área de várzea, Pigatto et al. (2001) observaram que também para essa gramínea foram necessários de 10 a 13 dias para o surgimento de uma nova folha. As equações de regressão, os coeficientes de determinação e as médias encontradas para as variáveis DP e produção de MS, nos três cortes do capim-Pojuca, são apresentadas na Tabela 2.

A densidade de perfilhos e a produção de MS em função das doses de N, no primeiro corte, foram melhor explicadas por equações de regressão quadráticas.

A densidade de perfilhos mais elevada foi obtida com a aplicação de $304 \mathrm{mg} / \mathrm{dm}^{3}$ de $\mathrm{N}$, para um valor estimado de 70,31 perfilhos/vaso. Para a produção de MS, o ponto de máxima foi alcançado com a dose de $320,78 \mathrm{mg} /$ $\mathrm{dm}^{3}$ de N, equivalente a 23,40 g/MS/vaso.

Assim como nas demais variáveis estudadas no primeiro corte, verificou-se redução no desenvolvimento das plantas quando a dose mais elevada de $\mathrm{N}$ foi aplicada. De acordo com Gomide \& Gomide (2001), diminuição na DP e na produção de MS após o ponto de máxima, como observado no primeiro corte, também pode estar relacionada ao IAF crítico exteriorizado em função da irrigação dos vasos e pela alta disponibilidade de $\mathrm{N}$.

Nos segundo e terceiro cortes, a DP e a produção de MS do capim-Pojuca aumentaram linearmente em resposta às doses de $\mathrm{N}$ aplicadas, podendo-se inferir que o teor de $\mathrm{N}$ no solo dos vasos que receberam 400 $\mathrm{mg} / \mathrm{dm}^{3}$ diminuíram a níveis adequados pela remoção de nutrientes em função direta da produtividade no primeiro corte.

Segundo Gomide (1994), deve-se fracionar a quantidade total do adubo em duas ou três aplicações, visando melhor utilização dos nutrientes aplicados. No presente trabalho, o fracionamento da adubação foi realizado com a finalidade aumentar a capacidade de utilização do fertilizante pelas plantas e impedir os efeitos do alto índice salino do fertilizante utilizado.

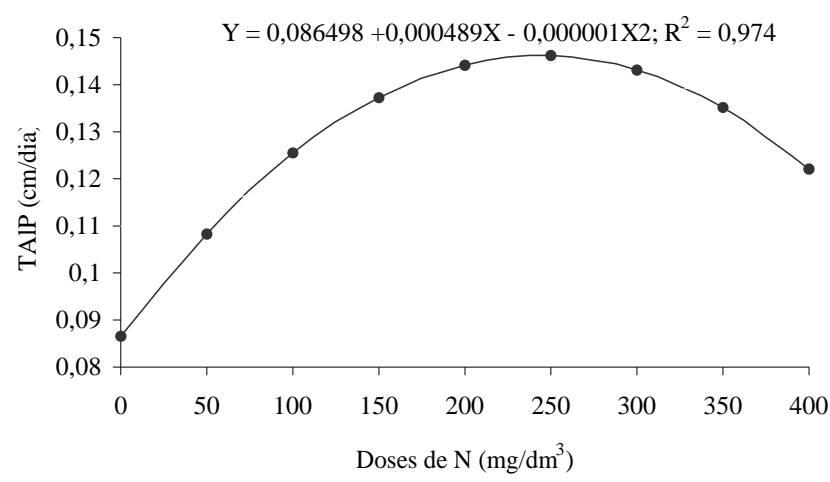

FIGURA 2 - Representação grátıca, equação de regressāo e coetıcıente de determınação para a taxa de alongamento de perfilho (TAlP) do capim-Pojuca em função de doses de N.

Ciênc. agrotec., Lavras, v. 30, n. 3, p. 554-561, maio/jun., 2006 
TABELA 2 - Equações de regressão, coeficientes de determinação $\left(\mathrm{R}^{2}\right)$ e médias estimadas da densidade de perfilhos e produção de MS do capim-Pojuca, nos três cortes.

\begin{tabular}{|c|c|c|c|}
\hline Cortes & Equações de regressão & $\mathbf{R}^{2}$ & Médias Estimadas \\
\hline & \multicolumn{3}{|c|}{ Densidade de Perfilhos (perfilhos/vaso) } \\
\hline $1^{\mathrm{o}}$ & $\ddot{Y}=22,317483+0,315651 X-0,000519 X^{2}$ & 0,993 & 49,79 \\
\hline $2^{\circ}$ & $\ddot{Y}=27,862500+0,123643 X$ & 0,936 & 49,50 \\
\hline \multirow[t]{2}{*}{$3^{\circ}$} & $\ddot{Y}=19,2875000+0,095946 X$ & 0,971 & 36,46 \\
\hline & \multicolumn{3}{|c|}{ Produção de MS (g/vaso) } \\
\hline $1^{\mathrm{o}}$ & $\ddot{Y}=6,881716+0,103293 X-0,000161 X^{2}$ & 0,993 & 15,58 \\
\hline $2^{\circ}$ & $\ddot{Y}=7,576250+0,056109 X$ & 0,981 & 17,39 \\
\hline $3^{\circ}$ & $\ddot{Y}=21,6223+0,075158 X$ & 0,961 & 25,51 \\
\hline
\end{tabular}

Estudos têm mostrado resposta positiva do perfilhamento e da produção de MS à adubação nitrogenada. Pinto (1982) observou em Paspalum guenoarum Arech uma produção de 399 perfilhos $/ \mathrm{m}^{2}$ quando não foi realizada adubação nitrogenada e 511 perfilhos $/ \mathrm{m}^{2}$ após a adubação com $300 \mathrm{~kg} / \mathrm{ha}$ de N. Da mesma forma, avaliando a resposta de Paspalum notatum Flügge var. latiflorium à disponibilidade de N, Nabinger et al. (2003) encontraram valores de 7,$6 ; 13,0 ; 24,0$ e 43,0 perfilhos por planta quando adicionados 37,$5 ; 75 ; 150$ e $300 \mathrm{mg} / \mathrm{dm}^{3}$ de $\mathrm{NH}_{4} \mathrm{NO}_{3}$, respectivamente.

Em estudos realizados no campo, o capim-Pojuca tem apresentado altas produções de MS. Pizarro \& Carvalho (1992), citados por Kardec (2002), observaram que o capim-Pojuca se destacou entre as 15 gramíneas avaliadas quanto à produção de MS total em um Gleissolo Háplico, produzindo 26 t/ha na estação chuvosa. Em um estudo realizado entre janeiro de 2002 e julho de 2003, Caravali et al. (2004), avaliando taxas de acúmulo de MS de cultivares de gramíneas e leguminosas forrageiras no Acre, observaram que o capim-Pojuca apresentou produções de MS acima de $10.800 \mathrm{~kg} / \mathrm{ha} / \mathrm{ano}$, com taxa de acúmulo de MS superior a $30 \mathrm{~kg} / \mathrm{ha} / \mathrm{dia}$.

\section{CONCLUSÃO}

Conclui-se que a aplicação de $200 \mathrm{mg} / \mathrm{dm}^{3}$ de N é indispensável para um bom crescimento e boa produção de MS do capim-Pojuca, sendo desnecessário elevar o nível de saturação por bases do solo acima de $40 \%$ em Gleissolo háplico.

\section{REFERÊNCIAS BIBLIOGRÁFICAS}

ACOSTA, G.; DEREGIBUS, V. A. Nitrogen fertilization in Paspalum dilatatum, Poir: herbage production, nutritive value and structural characteristics. In: INTERNATIONAL GRASSLAND CONGRESS, 19., 2001, São Pedro. Anais... Piracicaba: FEALQ/ESALQ, 2001. CD-ROM.

ASSOCIATION OF OFFICIAL AGRICULTURAL CHEMISTS. Official Methods of the Association of Official Analytical Chemists. 15. ed. Washington, 1990. v. $1,684 \mathrm{p}$.

CARAVALI, J.; SALES, M. F.; VALENTIM, J. F. Taxas de acúmulo de matéria seca de gramíneas e leguminosas forrageiras no Acre. In: REUNIÃO ANUAL DA SOCIEDADE BRASILEIRA DE ZOOTECNIA, 41., 2004, Campo Grande. Anais... Campo Grande: SBZ, 2004. CD-ROM.

CARNEVALLI, R. A. Dinâmica da rebrotação de pastos de capim Monbaça submetidos a regimes de desfolhação intermitentes. 2003. 136 f. Tese (Doutorado) - Escola Superior de Agricultura de Luiz de Queiroz, Piracicaba, 2003.

CHAPMAN, D. F.; LEMAIRE, G. Morphogenetic and structural determinants of plant regrowth after defoliation. In: BAKER, M. J. (Ed.). Grasslands for our world. Wellington: SIR, 1993. p. 55-64.

COELHO, S. J. Influência de tipo de muda, espaçamento e adubação fosfatada no gramado de grama batatais (Paspalum notatum Flugge). 1994. 61 f. Dissertação (Mestrado) -Escola Superior de Agricultura de Lavras, Lavras, 1994. 
COMISSÂO DE FERTILIDADE DO SOLO DO ESTADO DE MINAS GERAIS. Recomendações para o uso de corretivos e fertilizantes em Minas Gerais: $5^{\text {a }}$ aproximação. Viçosa: EPAMIG/UFV, 1999. 359 p.

CORSI, M.; NÚSSIO, L. G. Manejo do capim elefante. In: SIMPÓSIO SOBRE MANEJO DA PASTAGEM, 10., 1991, Piracicaba. Anais... Piracicaba: FEALQ, 1994. p. 87-116.

COSTA, N. L.; PAULINO, V. T.; RODRIGUES, A. N. A. Nutrientes limitantes ao crescimento de Paspalum atratum BRA-009610. In: REUNIÃO ANUAL DA SOCIEDADE BRASILEIRA DE ZOOTECNIA, 35., 1998, Botucatu. Anais... Botucatu: SBZ, 1998. p. 608-610.

EMPRESA BRASILEIRA DE PESQUISA AGROPECUÁRIA. Capim-Pojuca: capim nativo de alta produtividade. Brasília, DF, 2000.

FERREIRA, D. F. SISVAR - Sistema de Análise de Variância para Dados Balanceados. Lavras: UFLA, 1999. Software não publicado.

GASTAL, F.;LEMAIRE, G. Study of a tall fescue sward grown under nitrogen deficiency conditions. In: MEETING OF THE EUROPEAN GRASSLAND FEDERATION, 12., 1988, Dublin. Proceedings... Belclare: Irish Grassland, 1988. p. 323-327.

GOMIDE, J. A. Adubação de pastagens estabelecidas. In: SIMPÓSIO SOBRE MANEJO DA PASTAGEM, 7., 1994, Piracicaba. Anais... Piracicaba: FEALQ, 1994. p. 33-60.

GOMIDE, J. A.; GOMIDE, C. A. Utilização e manejo de Pastagem. In: REUNIÃO ANUAL DA SOCIEDADE BRASILEIRA DE ZOOTECNIA, 38., 2001, Piracicaba. Anais...Piracicaba: FEALQ, 2001. CD-ROM.

KALMBACHER, R. S.; KRETSCHMER, A. Suerte Atra Paspalum. In: INTERNATIONAL CONFERENCE ON LIVESTOCK IN TROPICS, 1995, Gainesville. Proceedings... Florida: University of Florida, 1995. p. 13-21.

KALMBACHER, R. S.; MULLAHEY, J. J.; MARTIN, F. M. Effect of clipping on yield and nutritive value of "Suerte" Paspalum atratum. Agronomy Journal, Madison, v. 89, n. 3, p. 476-481, May/June 1997.

KARDEC, A. B. Avaliações agronômicas de genótipos de Paspalum spp no âmbito dos cerrados. 2002. 288 f. Tese
(Doutorado) - Universidade Estadual de São Paulo, Jaboticabal, 2002.

LANGER, R. H. M. How grasses grow. London: Edward Arnold, 1972. 60 p. (Studies in Biology, 34).

NABINGER, C.; SANTOS, R. J.; FEIJÓ, C. C. L. Resposta de Paspalum notatum var. latiflorium à disponibilidade de nitrogênio: I. morfogênese. In: REUNIÃO ANUAL DA SOCIEDADE BRASILEIRA DE ZOOTECNIA, 40., 2003, SantaMaria. Anais... Santa Maria: SBZ, 2003. CD-ROM.

NERES, M. A.; MESQUITA, E. E.; FUJI, P. R. H. Características morfológicas de cultivares de Brachiaria brizanta com ou sem nitrogênio na estação das águas. In: REUNIÃO ANUAL DA SOCIEDADE BRASILEIRA DE ZOOTECNIA, 41., 2004, Campo Grande. Anais... Campo Grande: SBZ, 2004. CD-ROM.

PIGATO, A. G. S.; QUADROS, F. A. L. F.; DULIO, G. B. Frequiência de pastejo em azevém anual (Lolium multiflorum), trevo-branco (Trifolium repens) e Paspalum urvillhei em área de várzea, Santa Maria, RS. In: REUNIÃO ANUAL DA SOCIEDADE BRASILEIRA DE ZOOTECNIA, 38., 2001, Piracicaba. Anais... Piracicaba: FEALQ, 2001. CD-ROM.

PINTO, J. C. Nitrogênio e métodos de semeadura no rendimento de sementes de Paspalum guenoarum Arech. 1982. $140 \mathrm{f}$. Dissertação (Mestrado em Agronomia) - Universidade Federal do Rio Grande do Sul, Porto Alegre, 1982.

PINTO, J. C.; GOMIDE, J. A.; MAESTRI, M. Crescimento de folhas de gramíneas forrageiras tropicais, cultivadas em vasos, com duas doses de nitrogênio. Revista da Sociedade Brasileira de Zootecnia, Viçosa, v. 23, n. 3, p. 327-332, maio/jun. 1994.

PRIMAVESI, O.; PRIMAVESI, A. C.; CORREA, A. L.; SILVA, C. H. Composição bromatológica de coastcross submetido a diferentes doses de nitrogênio. In: REUNIÃO ANUAL DA SOCIEDADE BRASILEIRA DE ZOOTECNIA, 38., 2001, Piracicaba. Anais... Piracicaba: FEALQ, 2001. CD-ROM.

PUPO, N. H. I. Manual de pastagens forrageiras. São Paulo: Instituto Campineiro de Ensino Agrícola, 1995. 235 p.

QUARIM, C. L.; VALLS, J. F. M.; URBANI, M. H. Cytological and reproductive behaviour of "Paspalum atratum", a promising forage grass for the tropcs. Tropical Grasslands, Brisbane, v. 31, p. 114-116, 1997. 
SANTOS, M. V. F.; DUBEUX JÚNIOR, J. C. B.; SILVA, C.; SANTOS, S. F.; FERREIRA, R.L.C.; MELLO, A.C.L.; FARIAS, I.; FREITAS, E.V. Produtividade e composição química de gramíneas tropicais na Zona da Mata de Pernambuco. Revista da Sociedade Brasileira de Zootecnia, Viçosa, v. 32, n. 4, p. 821-827. jul./ago. 2003.

SBRISSIA, A. F. Morfogênese, dinâmica de perfilhamento e de acúmulo de forragem em pasto de capim-Marandu sob lotação contínua. 2004. 171 f. Tese (Doutorado) - Escola Superior de Agricultura de Luiz de Queiroz, Piracicaba, 2004.

SIQUEIRA, C. Calagem para plantas forrageiras. In: SIMPÓSIO SOBRE CALAGEM EADUBAÇÃO DE PASTAGENS, 1., 1985, Nova Odessa. Anais... Piracicaba: POTAFOS, 1986. p. 77-92.
SOARES, T. V.; FRANÇA, A. F.; BORGES, A. R. L. Avaliação da produção de massa seca, eficiência e recuperação do nitrogênio do capim tanzânia em duas alturas de corte. In: REUNIÃO ANUAL DA SOCIEDADE BRASILEIRA DE ZOOTECNIA, 40., 2003, Santa Maria. Anais... Santa Maria: SBZ, 2003. CD-ROM.

VALE, F. R.; GUILHERME, L. R. G.; GUEDES, G. A. A. Fertilidade do solo: dinâmica e disponibilidade dos nutrientes de plantas. Lavras: UFLA/FAEPE, 1997. $171 \mathrm{p}$.

VILELA, L.; SOARES, W. V.; SOUZA, D. M. G. Calagem e adubação de pastagens na região do cerrado. Planaltina: Embrapa CPAC, 1998. 16 p. (Circular técnica, 37). 